\title{
Personality Disorders, Narcotics, and Stimulants; Relationship in Iranian Male Substance Dependents Population
}

\author{
Simasadat Noorbakhsh ${ }^{1,}$; Zahra Zeinodini ${ }^{1}$; Zeynab Khanjani ${ }^{2}$; Hamid Poorsharifi ${ }^{2}$; \\ Sepideh Rajezi Esfahani ${ }^{1}$ \\ ${ }^{1}$ Behavioral Sciences Research Center, Imam Hoseyn Hospital, Shahid Beheshti University of Medical Sciences, Tehran, IR Iran \\ ${ }^{2}$ Department of Psychology, Tabriz University, Tabriz, IR Iran \\ ${ }^{*}$ Corresponding Author: Simasadat Noorbakhsh, Behavioral Sciences Research Center, Shahid Beheshti University of Medical Sciences, Tehran, IR Iran. Tel: +98-2177553047, \\ Fax: +98-2177553047, E-mail: sima.nourbakhsh@gmail.com
}

Received: September 29, 2014; Revised: October 16, 2014; Accepted: October 30, 2014

\begin{abstract}
Background: Individuals with certain personality disorders, especially the antisocial and borderline personality disorders, are more prone to substance use disorders.

Objectives: Regarding the importance of substance use disorders, this study aimed to explore the association between personality disorders and types of used drugs (narcotics and stimulants) in Iranian male substance users.

Patients and Methods: The current study was a correlation study. We evaluated 285 male substance users and excluded 25 according to exclusion criteria. A total of 130 narcotic users and 130 stimulant users were recruited randomly in several phases from January 2013 to October 2013. All participants were referred to Substance Dependency Treatment Clinics in Tehran, Iran. Data collection process was accomplished by means of clinical interview based on DSM-V criteria for substance use disorders, Iranian version of addiction severity index (ASI), and Millon clinical multi-axial inventory-III (MCMI-III). Data were analyzed by SPSS 21 using Pearson correlation coefficient and regression, the.

Results: There was a significant correlation between stimulant use and histrionic personality disorder $(\mathrm{P}<0.001)$ and antisocial and narcissistic personality disorders $(\mathrm{P}<0.05)$. In addition, correlation between avoidant, histrionic, and narcissistic personality disorders $(\mathrm{P}<0.05)$ and depressed, antisocial, and borderline personality disorders $(\mathrm{P}<0.001)$ with narcotics consumption were significant. In clusters, there was a significant correlation between cluster B personality disorders, and narcotic and stimulants consumption $(\mathrm{P}<0.001)$. In addition, this association was explored between cluster $\mathrm{C}$ personality disorder and narcotics $(\mathrm{P}<0.001)$.

Conclusions: The results of this study in terms of personality disorders and types of used drugs were in accordance with the previous studies results. It is necessary to design appropriate treatment plans for medical treatment of those with personality disorders.
\end{abstract}

Keywords: Substance-Related Disorders; Personality Disorders; Narcotics; Heroin Dependence; Morphine Dependence

\section{Background}

Before the third edition of DSM, substance and alcohol dependency were considered as symptoms of personality disorders (PDs). However, in the third edition, drug consumption was identified as "substance use disorders" (SUD) (1). From then on, psychologic comorbidities have been viewed as an important subject in drug consumption (2). The PDs are rigid, inflexible, and maladaptive behavior patterns, which are severe enough to cause significant impairments in functioning or internal distress. They are enduring and persistent style of behavior and thought, not atypical episodes (3). The high prevalence of DSM-IV PDs among those with SUDs was evidently indicated in the research literature $(4,5)$. A recent literature review (6) summarized prevalence rates and concluded that estimates of the overall axis II prevalence range from $34 \%$ to $73 \%$ in treated substance users, with and borderline PDs as the most prevalent ones.
A short review on previous studies revealed individuals with certain PDs, especially the antisocial PD, were more prone to SUD (7-9), and persons dependent to different types of drugs showed more PDs comorbidity $(10,11)$. One meta-analyze has shown that patients under medical treatment for SUD display more comorbidity with PDs than normal individuals do (12). Another study conducted by Grana et al. (13) showed the chronic drug consumers had higher scores in schizoid PD and antisocial PD than the functional consumers did. Considering the corroboration of the aforementioned reality, authors like San Narciso et al. (14) found the most frequently diagnosed PDs in heroin substance users undergoing methadone maintenance treatment were antisocial and borderline PD. In addition, Grana et al. (13) found that antisocial and schizoid traits are the most outstanding traits of heroin substance users and multidrug consumers. However,

Copyright (C) 2015, Iranian Red Crescent Medical Journal. This is an open-access article distributed under the terms of the Creative Commons Attribution-NonCommercial 4.0 International License (http://creativecommons.org/licenses/by-nc/4.0/) which permits copy and redistribute the material just in noncommercial usages, provided the original work is properly cited. 
cocaine use (15) is often associated with psychiatric comorbidity such as antisocial PD (24\%), major depressive disorder (18\%), and posttraumatic stress disorder (12\%). Applying Millon Clinical Multi-Axial Inventory-III (MCMIIII), Craig (16) focused on range of PDs in 443 individuals with drug dependency. In both groups, antisocial (60\%), passive-aggressive (34\%), and depressive PDs (32\%) were the most prevalent PDs. In a study on heroin users in Taiwan, $58.5 \%$ of men and $62.5 \%$ of women had at least one axis-I psychiatric disorder or antisocial PD (17).

It is generally accepted that substance users prefer drugs that have best effects on healing their personality problems and use other kind of drugs only when they are deprived of the preferred ones $(6,18)$. Evident reveals that drugs may be choose by a substance user due to their self-medicating effects (19). Robbins (20) points out that substance users use drug to reduce their social anxieties. He also argues that narcotics users may use them to overcome aggression. However, these suggestions about the specific association between psychological problems and drug choosing have not been scrutinized. Yet drugs are the most powerful means to change one's mental state because of their effects on minimizing psychological problems. Some patients abuse drugs to reduce anxieties, irritation, and depression. Therefore, in cases of self-medication, it would be better to consider a proper plan to solve fundamental problems (19).

This study aimed to determine the association between PDs and types of drugs in Iranian substance users. The PDs of cluster B, especially borderline and antisocial PDs, and SUD and its intensity were studied largely in previous studies. This study aimed to study all types of PD.

\section{Objectives}

No research has concentrated on comparing narcotics (including opium, shireh, heroin, and crack, a kind of compacted heroin made in Iran) with stimulants (as amphetamine, methamphetamine and cocaine) in Iran. Undoubtedly, any knowledge about the personal characteristic of these groups of drug users sheds new lights on the more effective medical and psychological treatment for better outcomes. Thus, if routine personality assessment improves outcomes of SUD treatment, the clinical implication will be increasing the use of PD assessment in SUD treatment settings (21).

\section{Patients and Methods}

Current study was a correlation study. To determine the sample size, the Cochran's sample size formula for correlation studies (22) was used (Equation 1, in which $\mathrm{T}=1.96$, $\mathrm{P}=0.5, \mathrm{q}=0.5$, and $\mathrm{d}=0.11)$. The minimum sample size needed to obtain statistically valid results was 79, and we added 51 more samples to obtain higher validity.

$$
n=\frac{T^{2} \mathrm{pq}}{d^{2}}
$$

The samples were male substance users aging 18 to 45 years, who met the DSM-V (23) criteria for SUDs and were in diverse treatment programs such as methadone maintenance therapy, buprenorphine therapy, and detoxification in private clinics for substance use treatment. The sample group was 260 substance users, 130 narcotics dependents and 130 stimulant dependents. They were selected randomly through several-phases sampling process. In first step, private clinics of substance dependency treatment were classified into four groups of north, east, west, and south clinics in Tehran, Iran. Then in each region, two clinics were selected conveniently regarding the clinic manager's tendency to participation in the study. Thus, patients were recruited from centers for substance dependency treatment in four regions of Tehran. Patients were recruited by general practitioners (GPs) working in these centers until the required sample was reached, without a quota of patients assigned for each center. The inclusion criteria were as follows: being male, 18 age of to 65 years, being able to understand and read Persian language, and willing to participate in the study. Exclusion criteria included schizophrenia and psychosis, incomplete questionnaire, and relapse in the preceding two days. Finally, 25 patients were excluded. Receiving medical treatment was not an exclusion criterion; however, treatment was not modified or increased during the study period. Diagnosis of drug dependency was made with structured interview according to Addiction Severity Index (ASI) and confirmation of the technical manager of the clinic, who were mostly GPs or psychiatrists. All of participants filed out MCMI-III to assess type of drug and PDs. Then, a psychiatrist or a clinical psychologist confirmed the result from MCMI-III by interviewing the patient.

\subsection{Instruments}

1) ASI: The ASI is a semi-structured interview for substance abuse assessment and treatment planning. The ASI is designed to gather valuable information about areas of a client's life that may contribute to their substance-abuse problems. The ASI was developed in 1980 by A. Thomas McLellan, along with collaborators from the University of Pennsylvania's center for the Studies of Addiction. The ASI was the first standardized assessment tool of its kind to measure the multiple dimensions of substance abuse. It has three categories: 1) Socio-demographic: sex, age, years of education, and main source of income; 2) Consumption: main substance, type of treatments, and years of consumption; and 3) Severity of dependency. Overall, studies typically conclude that the ASI is a consistent and accurate tool for assessing clients and their substance abuse issues. The ASI is able to successfully identify the client's problem area in which they are experiencing the greatest difficulties, such as alcohol or drug addiction, or legal or familial problems. Once a client's psychosocial issues are identified, an appropriate course of treatment should be administered. 
Noorbakhsh S et al.

Severity ratings are based on the following ten-point scale (range, 0 - 9):

$0-1$, No real problem; treatment is not indicated.

$2-3$, Slight problem; probably treatment is not necessary.

4 - 5, Moderate problem; some treatment is indicated.

$6-7$, Considerable problem; treatment is necessary.

8 - 9, Extreme problem; treatment is absolutely necessary.

The severity ratings scale allows the interviewer to determine the severity of a client's problem. The higher the score is, the greater the need for treatment in each area or immediate intervention will be. The ASI scores can be used to profile a client's problem areas and then plan an effective course of treatment (24).

2) MCMI-III:The MCMI-III is a psychologic assessment tool intended to provide information on psychopathology, including specific disorders outlined in the DSM-IV. It is intended for adults ( $\geq 18$ years old) with at least an eighthgrade reading levels who are currently seeking mental health services. The MCMI was developed and standardized specifically on clinical populations, ie, patients in psychiatric hospitals or people with existing mental health problems, and the authors are very specific that it should not be used with the general population or adolescents (25). However, there is a strong evidence that shows it still retains validity on non-clinical populations. Therefore, psychologists often administer the test to members of the general population. The MCMI differs from other personality tests in that it is based on theory and is organized according to a multi-axial format. Updates to each version of the MCMI coincide with revisions to the DSM (26).

It is composed of 175 true/false questions that reportedly take 25 to 30 minutes to complete. It was developed by Theodore Millon, Carrie Millon, Roger Davis, and Seth Grossman (27).

The test is modeled on four scales: 14 personality disorder scales; 10 clinical syndrome scales; five correction scales including three modifying indices (which determine the patient's response style and can detect random responding) and two random response indicators; and 42 Grossman's personality facet scales, based on Seth Grossman's theories of personality and psychopathology. The MCMI-III was updated in 2008, with a new norming sample of 752 individuals (52.8\% female; $76 \%$ Caucasian) with a wide range of clinical disorders. The scale development stage consisted of 600 of these individuals (48.8\% male; $84 \%$ Caucasian), and the cross-validation stage consisted of the remaining 398 individuals (49.5\% male, $81.7 \%$ Caucasian) (28).

Fourteen personality disorder scales correspond with Axis II diagnoses of the DSM-IV. They describe more pervasive conditions. They are broken down further into 11 basic clinical personality patterns (Scales 1 through $8 \mathrm{~B}$ ) and three severe personality pathology scales (scales $S$ through P) (Table 1$)$.
Table 1. Clinical Personality Patterns and Severe Personality Pathology Scales

\begin{tabular}{lc}
\hline Abbreviation & Description \\
\hline $\mathbf{1}$ & Schizoid \\
\hline AA & Avoidant \\
2B & Depressive \\
$\mathbf{3}$ & Dependent \\
$\mathbf{4}$ & Histrionic \\
$\mathbf{5}$ & Narcissistic \\
$\mathbf{6 A}$ & Antisocial (aggressive) \\
$\mathbf{6 B}$ & Sadistic \\
\hline $\mathbf{7}$ & Compulsive \\
$\mathbf{8 A}$ & Negativistic (passive-aggressive) \\
$\mathbf{8 B}$ & Masochistic (self-defeating) \\
$\mathbf{S}$ & Schizotypal \\
$\mathbf{C}$ & Borderline \\
$\mathbf{P}$ & Paranoid \\
\hline
\end{tabular}

The final validation stage includes convergent and discriminative validity of the test, which is assessed by correlating the test with similar/dissimilar instruments. Positive predictive value is the likelihood of being right given a test positive, which ranged from 0.30 (Masochistic) to 0.81 (Dependent). Sensitivity or the proportion of individuals that have a condition and are correctly identified ranged from 0.44 (negativistic) to 0.92 (paranoid).

Patients' raw scores are converted to base rate (BR) scores to allow comparison between the personality indices. The BR scores are essentially where each score fits on a scale of 1 through 115 , with the median score of 60 . Conversion to a BR score is relatively complex, and there are certain corrections that are administered based on each patient's response style.

The Modifying indices are scored using a complex system in which the patient's responses in the other scales are compared and the raw and BR scores are taken from this. However, the invalidity index is an exception and is not converted to a BR score (25-27). In Iran, the questionnaire has been normalized by Sharifi et al. (29).

\subsection{Ethical Aspects}

Informed consent was obtained from the participants. Before they give their consent, the patients were provided with a general overview of the aims and characteristics of the study. They were also informed that they were participating voluntarily, and that they could choose to withdraw at any time with the guarantee that they will continue to receive the treatment considered most appropriate by their clinic. The Study was approved by the ethical review board of the Behavioral Sciences Research Center of Shahid Beheshti University of Medical Sciences, Tehran, Iran (11.12.2013; ref: PI10/039). The results were used anonymously and all of the data were kept confidential in this study. 


\subsection{Statistics}

This research was a correlation study. The Statistics were analyzed both descriptively and inferentially. Applying Pearson correlation coefficient and linear regression in the inferential part, hypothesis of the research were examined.

\section{Results}

The average age of the stimulant and narcotics dependents was respectively 28.8 and 33.1 years. Half of the narcotic dependents were married $(n=67)$, one was divorced, and the rest were single $(n=63)$. In stimulant dependents, 42 were married, 73 were single, and 15 were divorced. Most of stimulant dependents were single while the married and single ones were nearly equal in narcotic dependents. Most of the narcotic dependents were jobless while most of stimulant dependents had job. Most of narcotic and stimulant dependents had diploma (certificate for secondary education graduates in Iran) or were secondary education undergraduates. In addition, frequency of narcotic dependents with diploma, associate degree, and bachelor degree was lower than that of stimulant dependents.
In order to explore the association between PDs and type of used drugs, Pearson correlation coefficient was applied with the results presented in two ways: for each $\mathrm{PD}$ and for each cluster.

As is shown in Table 2, there was a significant correlation between stimulant consumption and histrionic PD $(\mathrm{P}<0.001)$, and antisocial $\mathrm{PD}$ and narcissistic $\mathrm{PD}(\mathrm{P}<$ $0.05)$. In addition, there were significant correlations between narcotic consumption and histrionic, narcissistic, and avoidant $(\mathrm{P}<0.05$ for all), antisocial, borderline, and depressive PDs ( $\mathrm{P}<0.001$ for all).

According to Table 3, examining correlation coefficients between each cluster and type of drug revealed a significant correlation between cluster $\mathrm{B}$ and narcotics and stimulant consumption $(\mathrm{P}<0.001)$. On the other hand, the table shows a significant correlation between cluster $\mathrm{C}$ and narcotic consumption $(\mathrm{P}<0.001)$. No significant correlation was observed between cluster $\mathrm{A}$ and any drug.

The results of linear regression in Table 4 shows that avoidant, histrionic, narcissistic, depressive, antisocial, and borderline PDs play significant role in narcotic consumption. In addition, histrionic, antisocial, and narcissistic PDs can predict stimulant use.

Table 2. Correlation Coefficients Between Personality Disorders and Type of Used Drug

\begin{tabular}{lcc}
\hline Variant & Stimulant & Opium \\
\hline 1. Schizoid & 0.2 & 0.31 \\
\hline 2A. Avoidant & 0.32 & $0.51^{\mathrm{a}}$ \\
\hline 2B. Depressed & 0.1 & $0.6^{\mathrm{b}}$ \\
\hline 3. Dependent & 0.24 & 0.2 \\
\hline 4. Histrionic & $0.7^{\mathrm{b}}$ & $0.54^{\mathrm{a}}$ \\
\hline 5. Narcissistic & $0.47^{\mathrm{a}}$ & $0.43^{\mathrm{a}}$ \\
\hline 6A. Anti-Social (Aggressive) & $0.61^{\mathrm{a}}$ & $0.55^{\mathrm{b}}$ \\
\hline 7. Compulsive & 0.2 & 0.12 \\
\hline 8A. Negativistic (Passive-Aggressive) & 0.4 \\
\hline 8B. Masochistic (Self-Defeating) & 0.11 & 0.24 \\
\hline S. Schizotypal & 0.24 & 0.2 \\
\hline C. Borderline & 0.33 & 0.34 \\
\hline P. Paranoid & $0.57^{\mathrm{b}}$ & 0.23 \\
\hline
\end{tabular}

$\mathrm{a}_{\mathrm{P}}<0.05$.

$\mathrm{b}_{\mathrm{P}}<0.001$.

Table 3. Correlation Coefficients Between Clusters A, B, and C, and Type of Used Drugs

\begin{tabular}{lcc}
\hline Variant & Stimulant & Narcotics \\
\hline Cluster A & 0.2 & 0.11 \\
Cluster B & $0.53^{\mathrm{a}}$ & $0.6^{\mathrm{b}}$ \\
Cluster C & 0.3 & $0.7^{\mathrm{b}}$ \\
\hline
\end{tabular}

${ }^{\mathrm{a}} \mathrm{P}<0.05$.

$\mathrm{b}_{\mathrm{P}<0.001}$. 
Noorbakhsh S et al.

Table 4. Linear Regression between Personality Disorders and Type of Drugs

\begin{tabular}{|c|c|c|c|}
\hline Personality Disorders/Drug Type & No. & Regression Coefficient & Significance Surface \\
\hline \multicolumn{4}{|l|}{ Schizoid } \\
\hline Narcotic & 132 & -0.06 & 0.22 \\
\hline Stimulant & 153 & -0.02 & 0.88 \\
\hline \multicolumn{4}{|l|}{ Avoidant } \\
\hline Narcotic & 132 & $-0.20^{a}$ & 0.001 \\
\hline Stimulant & 153 & -0.12 & 0.25 \\
\hline \multicolumn{4}{|l|}{ Depressive } \\
\hline Narcotic & 132 & $-0.17^{\mathrm{a}}$ & 0.001 \\
\hline Stimulant & 153 & -0.29 & 0.06 \\
\hline \multicolumn{4}{|l|}{ Dependent } \\
\hline Narcotic & 132 & -0.08 & 0.60 \\
\hline Stimulant & 153 & -0.13 & 0.27 \\
\hline \multicolumn{4}{|l|}{ Histrionic } \\
\hline Narcotic & 132 & $-0.42^{\mathrm{a}}$ & 0.001 \\
\hline Stimulant & 153 & $-0.61^{\mathrm{a}}$ & 0.001 \\
\hline \multicolumn{4}{|l|}{ Narcissistic } \\
\hline Narcotic & 132 & $-0.45^{\mathrm{a}}$ & 0.001 \\
\hline Stimulant & 153 & $-0.29^{\mathrm{a}}$ & 0.001 \\
\hline \multicolumn{4}{|l|}{ Antisocial } \\
\hline Narcotic & 132 & $-0.29^{a}$ & 0.001 \\
\hline Stimulant & 153 & $-0.19^{a}$ & 0.001 \\
\hline \multicolumn{4}{|l|}{ Compulsive } \\
\hline Narcotic & 132 & -0.07 & 0.25 \\
\hline Stimulant & 153 & -0.05 & 0.94 \\
\hline \multicolumn{4}{|l|}{ Negativistic } \\
\hline Narcotic & 132 & -0.20 & 0.84 \\
\hline Stimulant & 153 & -0.03 & 0.81 \\
\hline \multicolumn{4}{|l|}{ Masochistic } \\
\hline Narcotic & 132 & -0.13 & 0.23 \\
\hline Stimulant & 153 & -0.12 & 0.28 \\
\hline \multicolumn{4}{|l|}{ Schizotypal } \\
\hline Narcotic & 132 & -0.29 & 0.05 \\
\hline Stimulant & 153 & -0.27 & 0.40 \\
\hline \multicolumn{4}{|l|}{ Borderline } \\
\hline Narcotic & 132 & $-0.32^{a}$ & 0.001 \\
\hline Stimulant & 153 & -0.09 & 0.34 \\
\hline \multicolumn{4}{|l|}{ Paranoid } \\
\hline Narcotic & 132 & -0.28 & 0.80 \\
\hline Stimulant & 153 & -0.05 & 0.04 \\
\hline
\end{tabular}

a P value $<0.001$.

\section{Discussion}

The aim of this study was to determine the association between PDs and types of drugs in Iranian male drug users. The research findings revealed that there was a significant association between PDs in cluster B and both narcotic and stimulant consumption, while PDs in cluster A

had no significant association with narcotic and stimulant consumption. On the other hand, PDs in cluster C also showed significant association only with narcotics (e.g. opium, heroin, and crack in Iran) consumption. As it was suggested, analyzing the association between cer- 
tain types of drugs with each PD proved that narcotic consumption was associated with histrionic, borderline, depressive, avoidant, antisocial, and narcissistic PDs, and stimulant usage was associated with narcissistic, antisocial, and histrionic PDs.

These findings were consistent with the previous studies. Study of PDs and drug of choice in a meta-analysis indicated that borderline and antisocial PDs in stimulant users, dependent, avoidant, schizoid, and borderline PDs in narcotics users, and in general, histrionic and narcissistic PDs were prevalent among patients with SUD $(6,30)$. In addition, the comorbidity of SUDs and PDs is established in many studies. For example, antisocial and borderline PDs, as the most common PDs in patients with SUD (6), have comorbidity of $18 \%$ and $17 \%$, respectively (31), and half of patients consuming buprenorphine have borderline PD (32). In addition, antisocial, borderline, and dependent PDs-cluster $B$ and $\mathrm{C}$-are the most common comorbidities in heroin users (33-38). On the other hand, cocaine users show more characteristics of schizoid and avoidant traits (39), or antisocial PD (19). It can be said that individuals in cluster $\mathrm{C}$ have different reasons for their tendency to narcotics in comparison with individuals in cluster B. In fact, persons in cluster B because of their illegal behavior (40), and persons in cluster $C$ due to their low self-esteem, self-dependency, self-sufficiency, and inferiority in social association are drown to narcotics consumption (41).

Some studies have proved that heroin users are more impulsive and aggressive than cocaine users $(42,43)$, while other have expressed no significant difference in personality traits between cocaine and heroin (44) or cannabis abusers (45). Researches consistently have provided the evidence of higher impulsivity and emotional instability in multi-drug abusers, and they had higher levels of antisocial, borderline, and passive aggressive PDs (41). Others have signified that narcotic users share characteristics including irresponsibility, snobbishness, ignoring others, and have PDs, especially antisocial and histrionic PDs (46). Other enquiries have shown that personality characteristics including reclusiveness, being antisocial, sensitive, and anxious, irresponsibility, and poor social adjustment and empathy are associated with risky behaviors such as drug use as a way to overcome negative moods and feelings (47). Most surveys have concluded that behaviors such as risky sexual behaviors and shared injections are associated with the above-mentioned characteristics (48). Trobst et al. (49) argued that risky behaviors are in fact, an attempts to reduce anxiety levels and obtain transitory tranquility and pain relief, which are resulted from negative emotions and feelings. These results suggest that most people who drink alcohol hazardously, or use drugs such as cocaine, marijuana, heroin and other narcotics have anxiety, isolation, and loneliness (50).

Generally, PDs usually accompany with drug and al- cohol consumption. Armstrong and Costello (51) found that $60 \%$ of drug users, drug abusers, and drug dependents have comorbid PDs. As long as having a psychiatric disorder $(52,53)$, especially PDs $(6,54)$, can significantly increase the risk of relapse, drop out, or poorer treatment outcomes, these patients need more specific treatment plans (55-57).

In conclusion, results of the present research were in accordance with previous ones in terms of PDs and types of consumed drugs. Antisocial and borderline PDs are prevalent in stimulant users, avoidant, dependent, schizoid, and borderline PDs in alcohol and narcotic users, and in general, histrionic and narcissistic PDs are prevalent in those with SUDs. In general, $34.8 \%$ to $73 \%$ of the treated substance users have comorbid PDs (6). According to Craig (16), Compton et al. (58), and Grant et al. (59), in each group, the prevalence of antisocial PD was significant. Armstrong and Costello (51) acknowledged the findings in teenagers. In this research, in comparison with stimulant consumption, narcotic consumption had higher rate of PDs. Finally, this conclusion could be drawn that self-medication effects of narcotics, due to the pain relieving and anxiety-reducing characteristics, can cover more PDs, while stimulants have more limited self-medicating effects.

The current study was the first study conducted on both narcotics and stimulant users about PDs on Iranian population; however, it study has some limitations. For instance, it has been conducted on men in Tehran and cannot be generalized to women or substance users of other cities. It included population between 18 to 45 years old and cannot generalize the results to teenagers or elderly. The same study can be conducted on women, teenagers, and population in other cities. Extensive research may include their family members' personality traits and culture.

\section{Acknowledgements}

We want to thank all the participants who made this study possible, and Dr Nooshin Shirkhanloo and Dr Parvaneh Ashrafian for providing support.

\section{Authors' Contributions}

Study concept and design: Sepideh Rajezi Esfahani; Acquisition of data: Zahra Zeinodini; Analysis and interpretation of data, drafting the manuscript, and administrative, technical, and material support: Simasadat Noorbakhsh; Critical revision of the manuscript for important intellectual content: Hamid Poorsharifi; Statistical analysis and study supervision:Zeynab Khanjani.

\section{Funding/Support}

Current study was funded by Behavioral Sciences Research Centre of Shahid Beheshti University of Medical Sciences. 
Noorbakhsh S et al.

\section{References}

1. Babor T. Substance-related problems in the context of international classificatory systems. Bature Alcohol Drug Relat Problems. 1992:83-97.

2. American Psychiatric Association.. DSM-III. American Psychiatric.; 1980.

3. Women CfSAT Branch Cs . Practical approaches in the treatment of women who abuse alcohol and other drugs.; 1994.

4. Compton WM, Conway KP, Stinson FS, Colliver JD, Grant BF. Prevalence, correlates, and comorbidity of DSM-IV antisocial personality syndromes and alcohol and specific drug use disorders in the United States: results from the national epidemiologic survey on alcohol and related conditions.JClin Psychiatry. 2005;66(6):677-85.

5. Moran P, Coffey C, Mann A, Carlin JB, Patton GC. Personality and substance use disorders in young adults. Br J Psychiatry. 2006;188:374-9.

6. Verheul R. Co-morbidity of personality disorders in individuals with substance use disorders. Eur Psychiatry. 2001;16(5):274-82.

7. Khantzian EJ, Treece C. DSM-III psychiatric diagnosis of narcotic addicts: Recent findings. Arch General Psychiatry. 1985;42(11):1067-71.

8. Conway KP, Swendsen JD, Rounsaville BJ, Merikangas KR. Personality, drug of choice, and comorbid psychopathology among substance abusers. Drug Alcohol Dependence. 2002;65(3):225-34.

9. Echeburua E, de Medina RB, Aizpiri J. Alcoholism and personality disorders: an exploratory study. Alcohol Alcohol. 2005;40(4):323-6.

10. Nace EP, Davis CW, Gaspari JP. Axis II comorbidity in substance abusers. Am J Psychiatry. 1991;148(1):118-20.

11. DeJong CAJ, Van den Brink W, Harteveld FM, van der Wielen EGM. Personality disorders in alcoholics and drug addicts. Comprehens Psychiatry. 1993;34(2):87-94.

12. O'Boyle M. DSM-III-R and Eysenck personality measures among patients in a substance abuse programme. Pers Individ Differ. 1995;18(4):561-5.

13. Grana JL, Munoz JJ, Navas E. Normal and pathological personality characteristics in subtypes of drug addicts undergoing treatment. Pers Individ Differ. 2009;46(4):418-23.

14. San Narciso GI, Gutiérrez E, Saiz PA, González MP, Bascarán MT, Bobes J. Evaluación de trastornos de la personalidad en pacientes heroinómanos mediante el Internacional Personality Disorders Examination (IPDE). Adicciones. 2000;12(1):43-56.

15. Falck RS, Wang J, Carlson RG, Eddy M, Siegal HA. The prevalence and correlates of depressive symptomatology among a community sample of crack-cocaine smokers. J Psychoactive Drugs. 2002;34(3):281-8.

16. Craig RJ. Prevalence of Personality Disorders among Cocaine and Heroin Addicts. Subst Abus. 2000;21(2):87-94.

17. Chiang SC, Chan HY, Chang YY, Sun HJ, Chen WJ, Chen CK. Psychiatric comorbidity and gender difference among treatmentseeking heroin abusers in Taiwan. Psychiatry Clin Neurosci. 2007;61(1):105-11.

18. Khantzian EJ. The self-medication hypothesis of addictive disorders: focus on heroin and cocaine dependence. Am J Psychiatry. 1985;142(11):1259-64.

19. Ford JD, Gelernter J, DeVoe JS, Zhang W, Weiss RD, Brady K, et al. Association of psychiatric and substance use disorder comorbidity with cocaine dependence severity and treatment utilization in cocaine-dependent individuals. Drug Alcohol Depend. 2009;99(1-3):193-203.

20. Robbins PR. Depression and drug addiction. Psychiatr Q. 1974;48(3):374-86.

21. Hesse M, Pedersen MK. Protocol: Personality assessment as a support for referral and case-work in treatment for substance use disorders (PASRC-study). BMC Psychiatry. 2008;8:30.

22. Nezu A, Nezu C. Evidence-based outcome research. A practical guide to conducting randomized controlled trials for psychosocial interventions. New York; 2008.

23. American Psychiatric Association.. DSM 5.; 2013.

24. Fureman B, Parikh G, Bragg A, McLellan A. Addiction severity index. A guide to training and supervising ASI interviews (5th ed) University of PA/Philadelphia VAMC, Center for Studies of Addiction.; 1990.
25. Millon T. Millon clinical multiaxial inventory manual. National Computer Systems.; 1983.

26. Millon T. Millon clinical multiaxial inventory: I \& II. Journal Counsel Dev. 1992;70(3):421-6.

27. Millon T, Millon C, Davis R, Grossman S. Millon clinical multiaxial inventory-III (MCMI-III), 2009

28. Pichon MF, Broet P, Magdelenat H, Delarue JC, Spyratos F, Basuyau JP, et al. Prognostic value of steroid receptors after longterm follow-up of 2257 operable breast cancers. Br J Cancer. 1996;73(12):1545-51.

29. Millon T, Bloom C. The Millon inventories: a practitioner's guide to personalized clinical assessment.New York City: Guilford Press; 2008.

30. Sharifi A, Moulavi H. The validity of MCMI-III (Millon, 1994) scales.; 2008.

31. Ross J, Teesson M, Darke S, Lynskey M, Ali R, Ritter A, et al. The characteristics of heroin users entering treatment: findings from the Australian treatment outcome study (ATOS). Drug Alcohol Rev. 2005;24(5):411-8.

32. McGovern MP, Xie H, Segal SR, Siembab L, Drake RE. Addiction treatment services and co-occurring disorders: Prevalence estimates, treatment practices, and barriers. J Subst Abuse Treat. 2006;31(3):267-75.

33. Sansone RA, Whitecar P, Wiederman MW. The prevalence of borderline personality among buprenorphine patients. Int J Psychiatr Med.2008;38(2):217-26.

34. Rodriguez-Llera MC, Domingo-Salvany A, Brugal MT, Silva TC, Sanchez-Niubo A, Torrens M, et al. Psychiatric comorbidity in young heroin users. Drug Alcohol Depend. 2006;84(1):48-55.

35. Fassino S, Daga GA, Delsedime N, Rogna L, Boggio S. Quality of life and personality disorders in heroin abusers. Drug Alcohol Depend. 2004;76(1):73-80.

36. Brooner RK, King VL, Kidorf M, Schmidt CJ, Bigelow GE. Psychiatric and substance use comorbidity among treatment-seeking opioid abusers. Arch Gen Psychiatry. 1997;54(1):71-80.

37. Franques P, Auriacombe M, Tignol J. [Addiction and personality]. Encephale. 2000;26(1):68-78.

38. Rounsaville BJ, Kranzler HR, Ball S, Tennen H, Poling J, Triffleman E. Personality disorders in substance abusers: relation to substance use. J Nerv Ment Dis. 1998;186(2):87-95.

39. Turner RJ, Gil AG. Psychiatric and substance use disorders in South Florida: racial/ethnic and gender contrasts in a young adult cohort. Arch General Psychiatr. 2002;59(1):43-50.

40. de Los Cobos JP, Sinol N, Banulus E, Batlle F, Tejero A, Trujols J. Personality traits of cocaine-dependent patients associated with cocaine-positive baseline urine at hospitalization. Am J Drug Alcohol Abuse. 2010;36(1):52-6.

41. Darke S, Ross J, Williamson A, Mills KL, Havard A, Teesson M. Borderline personality disorder and persistently elevated levels of risk in 36-month outcomes for the treatment of heroin dependence. Addiction. 2007;102(7):1140-6.

42. Conway KP, Kane RJ, Ball SA, Poling JC, Rounsaville BJ. Personality, substance of choice, and polysubstance involvement among substance dependent patients. Drug Alcohol Dependence. 2003;71(1):65-75.

43. Mccormick RA, Dowd ET, Quirk S, Zegarra JH. The relationship of NEO-PI performance to coping styles, patterns of use, and triggers for use among substance abusers. Addict Behav. 1998;23(4):497-507.

44. Donovan JM, Soldz S, Kelley HF, Penk WE. Four addictions: the MMPI and discriminant function analysis. J Addict Dis. 1998;17(2):41-55.

45. Craig RJ. Overview and current status of the Millon Clinical Multiaxial Inventory. J Pers Assess. 1999;72(3):390-406.

46. Greene RL, Adyanthaya AE, Morse RM, Davis LJ. Personality variables in cocaine- and marijuana-dependent patients. J Pers Assess. 1993;61(2):224-30.

47. Ameri, K. . Examining Personality Characteristics in Cloninger Systems in Two Groups of Addicts and Non-addicts.Tehran: Tarbiat Modares University; 2001.

48. Abdollah Zadeh, B. . Comparing Personality Factors, Problem-solving Methods and the experienced Stress rate in Addicts and Normal person.Tabriz: Tabriz University University; 2007. 


\section{Noorbakhsh S et al.}

49. Darke S, Williamson A, Ross J, Teesson M, Lynskey M. Borderline personality disorder, antisocial personality disorder and risk-taking among heroin users: findings from the Australian Treatment Outcome Study (ATOS). Drug Alcohol Depend. 2004;74(1):77-83.

50. Trobst KK, Herbst JH, Masters HL, Costa PT. Personality pathways to unsafe sex: Personality, condom use, and HIV risk behaviors. $J$ Res Pers. 2002;36(2):117-33.

51. Rostami R, Hddadi, P. . Practical Instruction of maintenance treatment with Methadone.Tehran: Tabalvor Publication; 2008.

52. Armstrong TD, Costello EJ. Community studies on adolescent substance use, abuse, or dependence and psychiatric comorbidity. J Consult Clin Psychol. 2002;70(6):1224.

53. Shanahan CW, Lincoln A, Horton NJ, Saitz R, Winter M, Same JH. Relationship of depressive symptoms and mental health functioning to repeat detoxification. J Subst Abuse Treat. 2005;29(2):117-23.

54. van den Bosch LM, Verheul R. Patients with addiction and personality disorder: Treatment outcomes and clinical implications. Curr Opin Psychiatry. 2007;20(1):67-71.

55. Bradizza CM, Stasiewicz PR, Paas ND. Relapse to alcohol and drug use among individuals diagnosed with co-occurring mental health and substance use disorders: a review. Clin Psychol Rev. 2006;26(2):162-78.

56. Flynn PM, Brown BS. Co-occurring disorders in substance abuse treatment: issues and prospects. J Subst Abuse Treat. 2008;34(1):36-47.

57. van den Bosch LM, Koeter MW, Stijnen T, Verheul R, van den Brink W. Sustained efficacy of dialectical behaviour therapy for borderline personality disorder. Behav Res Ther. 2005;43(9):1231-41.

58. McKay JR. Is there a case for extended interventions for alcohol and drug use disorders? Addiction. 2005;100(11):1594-610.

59. Compton WM, Cottler LB, Spitznagel EL, Abdallah AB, Gallagher T. Cocaine users with antisocial personality improve HIV risk behaviors as much as those without antisocial personality. Drug Alcohol Depend.1998;49(3):239-47.

60. Grant BF, Stinson FS, Dawson DA, Chou SP, Ruan WJ, Pickering RP Co-occurrence of 12-month alcohol and drug use disorders and personality disorders in the United States: results from the $\mathrm{Na}-$ tional Epidemiologic Survey on Alcohol and Related Conditions. Arch Gen Psychiatry. 2004;61(4):361-8. 